\title{
An Inverted Virtual Faculty Development Program for Remote Teaching: Pilot for Replication
}

\author{
Nagwa N Hegazy ${ }^{1 *}$, Saeed SA Soliman ${ }^{2}$, Samar A Ahmed ${ }^{3}$ and Marwa M Ahmed ${ }^{2}$ \\ ${ }^{1}$ Family Medicine Department, Faculty of Medicine, Menoufia University, \\ ${ }^{2}$ Family Medicine Department, Faculty of Medicine, Cairo University, \\ ${ }^{3}$ Forensic Medicine Department, Ain Shams University, Director Ain Shams University \\ *Corresponding Author: Nagwa Nashat Hegazy, Email: Nagwa.nashaat1@ med.menofia.edu.eg
}

\begin{abstract}
Background: Due to the COVID 19 pandemic, all the universities worldwide are experiencing a paradigm shift to online learning. Baby boomers and Generation X need to cope with the challenging transformation, so an emerging need for a faculty development program was needed towards achieving the goal of that transformation. Objectives: To describe and assess an inverted virtual faculty development program (VFDP) that was designed and implemented for the first time in the school to equip educators with the necessary technology competencies for remote online learning. Methods: An interventional prospective study held in a university setting post need analysis conduction to prioritize the required technological skills for faculty members. The program was designed to integrate five essential skills needed to by faculty members to teach remotely. The intervention comprised attending five virtual sessions after watching a predistributed material, then evaluated using the Kirkpatrick model.

Results: Almost $81 \%$ of faculty members completed the program and $80 \%$ of participants were satisfied with the content of the program. There was a statistically significant difference between the perceived ability of the participants to share and record video lectures before and after the VFDP ( $\mathrm{p}$ value $<0.001$ ). The percentage of the departments that applied the program components showed that $96 \%$ of them were able to record lectures. In addition, $80 \%$ of them were able to develop online quizzes. Conclusion: The inverted virtual faculty development program (VFDP) has supported the participating faculty in developing their needed technological competencies required to bridge the gap of remote teaching/learning.
\end{abstract}

Keywords: Academic training, Active learning, Distance, Education, Educational Technology, Program Evaluation.

\section{INTRODUCTION}

More than 120 countries have closed their educational institutions and suspended physical classes in response to health authorities' advice due to the viral spread of COVID-19 pandemic. Globally, theses closures impacted more than $60 \%$ of the students at different educational levels ${ }^{(1)}$.

Since mid-March 2020, universities in Egypt have been going through a radical shift from traditional faceto-face, in-class teaching to remote online teaching modality. Most universities have resorted to the remote online instruction to abide by the Egyptian government's decree of "nonstop teaching and learning" (2). Online learning management systems (LMSs) have been actively employed. The university council in Menoufia University in Egypt has been approved, emphasizing the use of "Microsoft teams" in teaching and formative assessment. Since the faculty have never used any online LMSs before, an immediate faculty development program was needed to ensure consistent implementation of the new policy ${ }^{(1)}$.

With the continued uncertainty in the instructional delivery with COVID-19 pandemic, the faculty development program (FDP) is a stand-alone educational program that aims to foster knowledge and professional skills of the university faculty. It hence ensures the faculty readiness, continued teaching skills and strategies, and the creation of a positive, self- directed, self-sustaining and collegial work environment (3). Development of the educator's technology competencies has set the stage for educator preparation programs to gauge current abilities and establish goals in order to meet the current needs ${ }^{(4)}$.

The inverted or inverted classroom method (ICM) in this pandemic sounds to be a suitable approach for delivery that ensures active learning through adult learning strategy. The flipped classroom (FC) also called inverted, reverse, or backward classroom has reaped universal consideration in the past few years as an unconventional and groundbreaking teaching and learning approach in medical education ${ }^{(5)}$.

It is mainly the inverse of the traditional classroom and homework elements where obligation for the attainment of knowledge lies with the scholars through videos, and other online resources. On the other hand the classroom is devoted to scholar centered activities ${ }^{(6)}$.

Inverted classroom displayed positive effects concerning engagement, motivation, overall satisfaction and learning outcomes ${ }^{(6)}$. This paper aims to describe a virtual faculty development program (VFDP) designed to equip educators with technology competencies shown to enhance educators' remote teaching in response to COVID-19 pandemic. 


\section{SUBJECTS AND METHODS}

\section{Ethical consent:}

An approval of the study was obtained from Menoufia University Ethical Committee. Every participant signed an informed written consent for acceptance of the operation. This work has been carried out in accordance with The Code of Ethics of the World Medical Association (Declaration of Helsinki) for studies involving humans.

The participants were informed about the program. The participant's name was kept anonymous. Participants were given the right to participate and withdraw at any time without any consequences.

Type of the study: Multistage study; first part; cross sectional and the second part is an interventional prospective cohort study.

Study sample: non-probability sampling based on the recruited number nominated by the departments.

Participants: Faculty members from 26 departments in the Medical School. The total existing faculty at the time of the study March 2020 were 446. In the first needs analysis part, the response rate was $57 \% \%$ (235 respondents). In the second part, systematically 3-4 participants from each department were recruited for the course resampling $21 \%$ of the faculty members (93 participants).

\section{Program details:}

Program planning:

After an emergent transition of the entire curriculum to an online platform, an urgent virtual faculty development program was launched as no previous online teaching guidance was provided in the School of Medicine. A needs assessment was conducted via a short predesigned online survey to assess the critical competencies that faculty members would need to enhance in that program. The Quality Assurance Unit and the Medical Education Center at the School of Medicine collaborated to design the suggested program. A convenient, non-random sample was drawn from 26 teaching departments in the Medical School. Each participant was asked to highlight three needed competencies from his or her point of view to enhance the faculty's online teaching. The survey responses were summarized, and the five highest-rated competencies were targeted in the program after adaptation with the medical education experts. The total available faculty at the time of this needs analysis were 446. The response rate was $57 \% \%$ (235 respondents).

\section{Program details:}

A centralized training program was proposed to ensure consistency in the online delivery of programs across the School of Medicine. The objective of the program was to equip educators with the fundamental technology competencies shown to promote remote learning during the time of COVID-19 pandemic as identified from the needs assessment.

A learner-centered approach was adopted by the Medical Education and Human Resources Development Center in the Medical School to implement the program. The planned program comprised five virtual sessions conducted via Zoom meeting application, with each session lasting for 2 hours. To maximize the benefits of the training time, participants were provided with key readings that included guides and handouts on basic principles of each domain before the sessions occurred. Thus, the sessions were hands-on experience to validate learning and provide feedback on the performance of participants. Each session integrated facilitated discussion and an assignment accompanied each discussion topic.

The discussion topics comprised the following: lecture recording using different applications such as PowerPoint presentations, the use of the available online meeting applications, online quiz generation, game-based learning, and the employment of the available LMS and discussions (As shown in table 1). 
Table 1. The list of key competencies in the program

\begin{tabular}{|c|c|c|}
\hline Competency & Acquired skill & Assignment \\
\hline $\begin{array}{l}\text { Learning } \\
\text { /teaching }\end{array}$ & $\begin{array}{l}\text { Lecture recording using different applications } \\
\text { Using the LMS and Discussions } \\
\text { Objectives: } \\
\text { 1. create a recorded lecture } \\
\text { 2.upload it on the LMS } \\
\text { 3. access, initiate and collaborate on the discussion board }\end{array}$ & $\begin{array}{l}\text { Faculty upload a recorded lecture } \\
\text { and create a discussion form for the } \\
\text { students on the LMS during the } \\
\text { training session }\end{array}$ \\
\hline $\begin{array}{l}\text { Student } \\
\text { E- } \\
\text { Engagement }\end{array}$ & $\begin{array}{l}\text { Using virtual platforms } \\
\text { Game based learning } \\
\text { Objectives: } \\
\text { Create a virtual meeting link } \\
\text { Initiate and maintain a virtual meeting } \\
\text { Conduct a game-based learning }\end{array}$ & $\begin{array}{l}\text { Faculty send a virtual meeting link } \\
\text { on the LMS during the training } \\
\text { session }\end{array}$ \\
\hline Assessment & $\begin{array}{l}\text { Developing an online quiz } \\
\text { Objectives: } \\
\text { 1. create a question } \\
\text { 2.build timed multiple-choice questions quiz } \\
\text { 3. access and share grades }\end{array}$ & $\begin{array}{l}\text { Faculty built a quiz during the } \\
\text { training session in the LMS course. }\end{array}$ \\
\hline $\begin{array}{l}\text { By the end of } \\
\text { 1. Identify rele } \\
\text { recordings } \\
\text { 2. Prepare and } \\
\text { 3. Use LMS fo } \\
\text { 4. Initiate a vir } \\
\text { 5. Maintain st } \\
\text { 6. Develop an } \\
\text { 7. Act as advo } \\
\text { Preparation: fact }\end{array}$ & $\begin{array}{l}\text { his program, faculty members will be able to: } \\
\text { vant key features of LMS, Forms, Audience response syst } \\
\text { ecord the lecture using two applications } \\
\text { posting and holding discussions } \\
\text { ual synchronous meeting using two applications } \\
\text { dent E- engagement during the course } \\
\text { automated grading online quiz } \\
\text { cate for self-learning and students learning } \\
\text { lty had to watch a short video on the assigned topic and rea }\end{array}$ & $\begin{array}{l}\text { ms and applications used for lecture } \\
\text { the online materials. }\end{array}$ \\
\hline
\end{tabular}

\section{Program implementation}

After the program objectives were determined, and the course content was designed, each department nominated three to four faculty members to participate in the program. The program dates were decided in correspondence to the faculty's busy schedule. Due to the limited resources, free applications and tools were chosen (e.g. zoom meeting applications and Microsoft forms). The VFDP was conducted via Zoom meetings application during the lockdown time. It had five training sessions, each lasting for two hours. It was usually scheduled early in the morning to ensure better internet connection. Each training session included 15 to 20 participants for the sake of better interaction and engagement. The virtual training program was repeated five times to meet the faculty needs. VFDP provided faculty with the opportunity to digitize the content. For example, they created slides and videos for their online classes. Production resources for digitizing content (for example, slides and video). Each time, the program lasted for ten days. 75 out of 93 faculty members completed the program resembling $81 \%$.

\section{Program monitoring:}

In terms of perceived educational gains, the participants' satisfaction was gauged at the end of the program by the trainers and by the participants (e.g. trainer observation for the achieved tasks and participants' pre- and post-training questionnaire. In addition, learning management systems were monitored to follow up on the implementation of the competencies. Application of the learning to practice was measured by the percentage of the departments applying the program content through weekly follow-ups on the LMS using a previous approved checklist.

The last step was the evaluation; participants' satisfaction in terms of perceived educational gain was the first level of Kirkpatrick Model (reaction). Demonstration of the participants' knowledge and skills, as evaluated by trainers and trainees was considered the second level of Kirkpatrick Model (learning) (7). Application of the program into practice was the third level of the model and was measured by the percentage of the departments that applied the program content as measured by a structured checklist. The checklist was developed by the Medical Education and Human Resources Development Center (MEHRDC) for faculty reporting and follow up. It was used to follow up the participants learning and application through the LMS. The study flow chart is shown in figure 1 . 


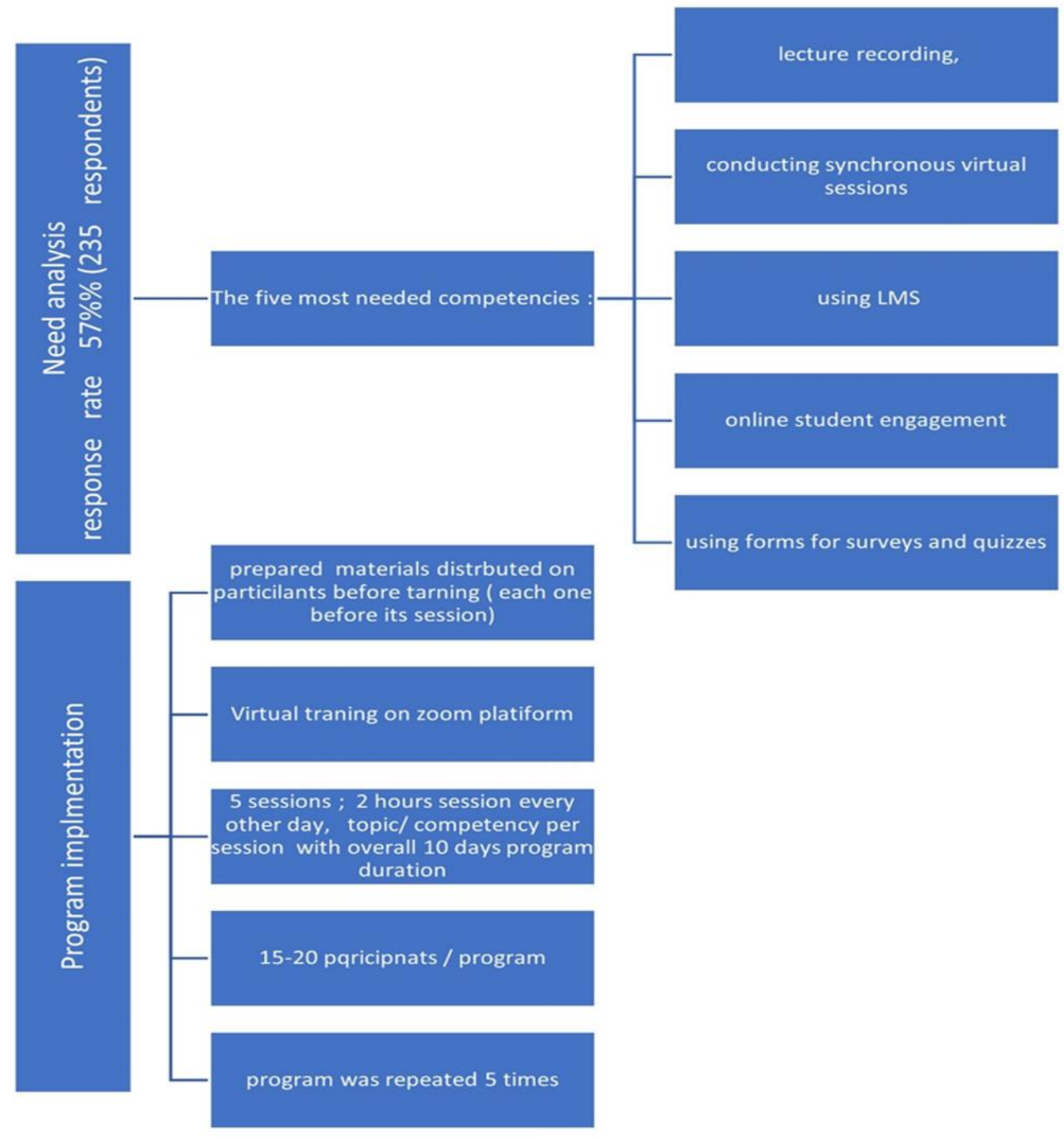

Figure 1: The study flow chart

\section{Statistical analysis}

The data were collected, tabulated, and statistically analyzed using an IBM personal computer with Statistical Package for the Social Sciences (SPSS) version 23. Qualitative data were expressed in the form of percentages and analyzed using a Chi-squared test $\left(\mathrm{X}^{2}\right)$ to detect the relation between different qualitative variables. A probability value (P-value) less than 0.05 was considered statistically significant and was considered highly statistically significant if $(\mathrm{P}<0.01)$.

\section{RESULTS}

Regarding participants' satisfaction, $80 \%$ of the participants were satisfied with the content of the program as highlighted in figure 2 . More than $75 \%$ of the participants deemed the production resources beneficial figure 3 . 


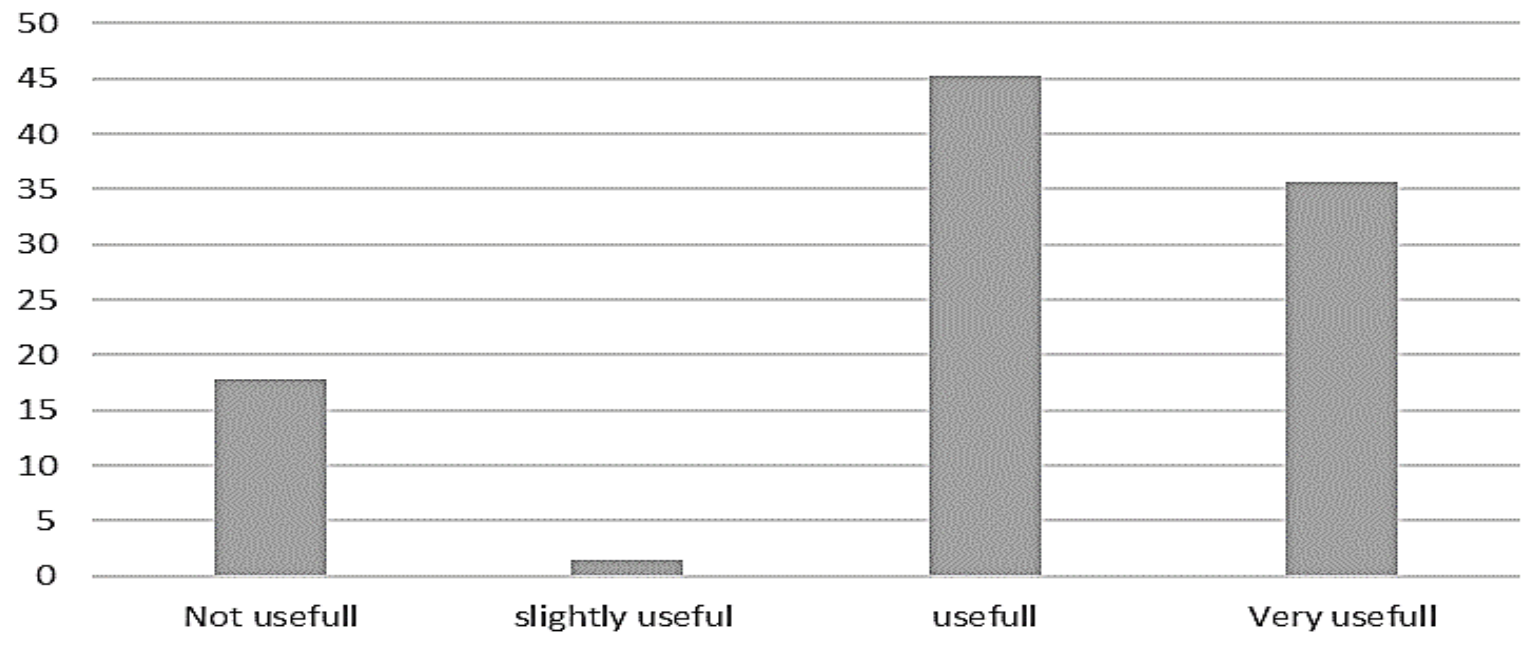

Figure 2. Degree of participants" satisfactions toward the program content

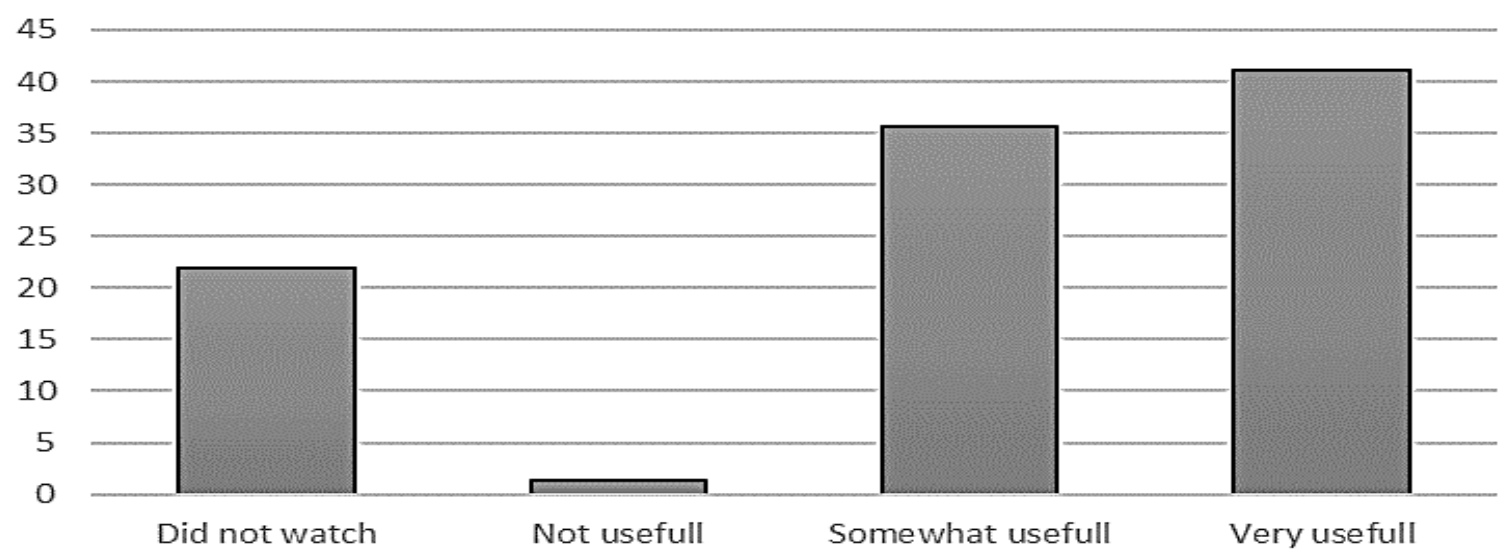

Figure 3. Ratings of the usefulness of the production resources

Table 2 shows that there was a statistically significant difference between the perceived ability of the participants to share and record video lectures before and after the VFDP.

Table 2. Comparison of participants responses before and after training

\begin{tabular}{|c|c|c|c|c|}
\hline & Pre-survey $n=93$ n (\%) & Post-Survey $n=75$ n $(\%)$ & P Value & $\mathbf{X}^{2}$ \\
\hline \multicolumn{5}{|c|}{ Ability to record video lectures } \\
\hline Did not record lectures & $10(10.8)$ & $9(12.3)$ & \multirow[t]{4}{*}{$<0.001$} & \multirow[t]{4}{*}{56.4} \\
\hline Cannot record lectures & $4(4.3)$ & $3(4.1)$ & & \\
\hline Can record with difficulty & $48(51.6)$ & $0(00.0)$ & & \\
\hline Can do with ease & $31(33.3)$ & $61(83.6)$ & & \\
\hline \multicolumn{5}{|c|}{ Ability to share/upload video lectures } \\
\hline Did not upload lectures & $17(18.3)$ & $14(19.2)$ & \multirow[t]{4}{*}{$<0.001$} & \multirow[t]{4}{*}{53.8} \\
\hline Cannot upload & $9(9.7)$ & $4(5.5)$ & & \\
\hline Can upload with difficulty & $42(45.2)$ & $0(00.0)$ & & \\
\hline Can Upload with ease & $25(26.9)$ & $55(75.4)$ & & \\
\hline
\end{tabular}

Percentage of departments application of the program components showed that $100 \%$ of them were able to do lecture recording using different applications that was followed by developing an online quiz in $80 \%$ of them (Figure 4 ). 


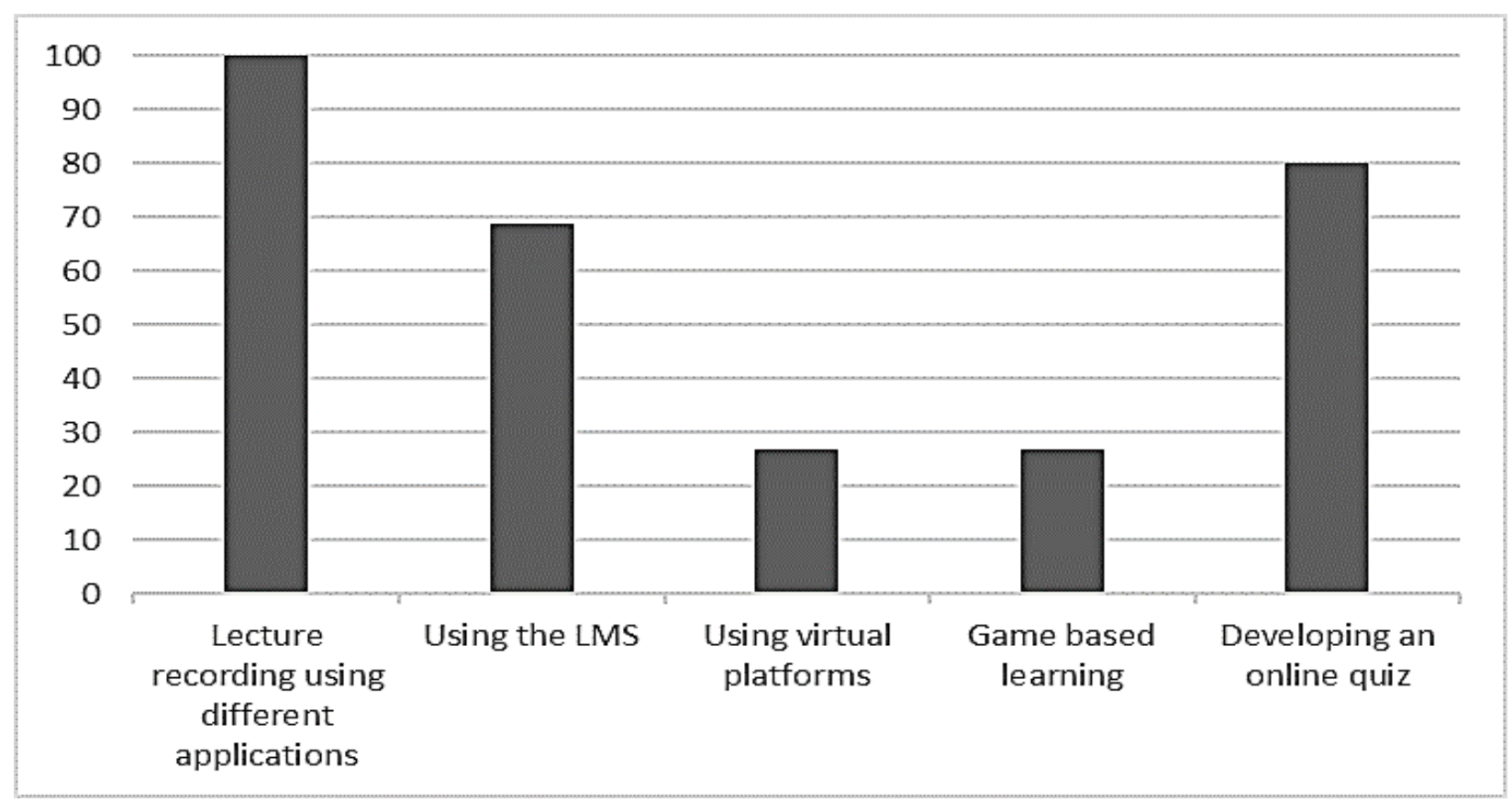

Figure 4. Percentage of departments' application of the program components

\section{DISCUSSION}

In the wake of coronavirus pandemic, the universities worldwide have experienced a paradigm shift to online teaching. The VFDP has proven effective in enhancing the faculty's skills and in developing the required competencies as indicated by the in-training evaluation and post-training monitoring ${ }^{(8)}$.

However, the most significant challenge to the success of any VFDP is the participants' underestimation of its value and the overconfidence in their skills ${ }^{(7)}$. The rapid shift to an online platform has led to feelings of inadequacy and frustration among faculty. This entailed that faculty sought to gain new knowledge and to enhance their skills in this new teaching environment. The perceived faculty needs from the need's assessment was an integral factor of the success of the program. Beside that some of these needs were described in other studies as an emerging faculty needs for enhancing student engagement on a virtual platform (8) with a primary focus on teaching improvement ${ }^{(9)}$.

A virtual faculty development can be an effective method to train the faculty on the use of new technologies and teaching modalities ${ }^{(10)}$. In our study, $80 \%$ of the participants were satisfied with the content of the program, and there was a statistically significant difference between the participants' perceived ability of recording video lectures and sharing them before and after VFDP. The incorporation of technological resources such as virtual platforms and hypermedia resources, combined with other innovative, methodological techniques, have enriched the training and learning process ${ }^{(11-13)}$.

Most importantly, skilled instructors who have experience with online teaching were chosen to implement the program. Following was the preparation of the training videos. An external coordinator was responsible for managing the program and addressing the trainers and trainees' inquiries and needs.

Designed after the Kirkpatrick model for planning and implementing an effective training program (11), our program began with a need's assessment of the faculty. The five top-ranked competencies were lecture recording, conducting synchronous virtual sessions, using LMS, online student engagement and using forms for surveys and quizzes. Adjustments were made to the content to fit the context of online teaching setting and the nature of generation $\mathrm{Z}$. Being familiar with social media and having a shorter attention span required a more technological engagement tool. To this end, the most useful tools are audience response systems such as Kahoot (which was used as ONE example of educational games in the methods). Besides, both synchronous and asynchronous discussion forums on the LMS, and quizzes enhance the learners' engagement. Finally, automatically graded quizzes may be used frequently during the teaching sessions to improve the learners' engagement and offer a formative way to assess the learning process ${ }^{(12) .}$

After the program objectives were determined, and the course content was designed, each department nominated three to four faculty members to participate in the program. The program dates were decided in correspondence to the faculty's busy schedule. Due to the limited resources, free applications and tools were chosen (e.g., zoom meeting applications and Microsoft forms). The incorporation of technological resources such as virtual platforms and hypermedia resources, combined with other innovative, methodological techniques, have enriched the training and learning process ${ }^{(13)}$. Most importantly, skilled instructors who have experience with online teaching were chosen to implement the program. Following was the preparation of the training videos. An external coordinator was responsible for managing the program and addressing 
the trainers and trainees' inquiries and needs.

The last step was the evaluation; participants' satisfaction in terms of perceived educational gain was the first level of Kirkpatrick Model (reaction) ${ }^{(11)}$. Demonstration of the participants' knowledge and skills, as evaluated by trainers and trainees was considered the second level of Kirkpatrick Model (learning) (11). Application of the program into practice was the third level of the model and was measured by the percentage of the departments that applied the program content as measured by a structured checklist. Data collated from the checklists have highlighted department adherence to the educational strategies and it shed the light on few key points towards the VFDP in terms of individual variations, preparedness and acceptance. This is in agreement with Samarasekera et al. (14), who encouraged that leveraging the use of technology should be tremendously encouraged to prepare the faculty members during critical or emergency situation.

\section{Limitations of the study:}

The current study requires an extended period to evaluate the impact of the program on students' learning. Though, we expected that it will promote an immediate organizational needed change. Besides, the methodological intervention was in one university.

\section{CONCLUSION}

The VFDP is likely to have enhanced the teaching skills of the faculty skills and developed their required technological competencies. The designed VFDP can be implemented in other Egyptian universities to help the Egyptian faculty members cope with the switch to the online teaching amid COVID-19 19 pandemic. Future studies addressing the long-term impact of this educational program should include a longitudinal follow up to assess the retention of knowledge and application of the skills. The current generation of health professional educators has a unique opportunity to shape the future of health professional education and the impact that it will have on the world's emerging innovators.

\section{ACKNOWLEDGEMENTS}

Authors acknowledge participants cooperation.

Financial support and sponsorship: Nil.

Conflict of interest: Nil.

\section{REFERENCES}

1. UNESCO (2020): Education: From disruption to recovery. Available at: https://en.unesco.org/covid19/educationresponse
2. Hodges $\mathbf{C}$, Moore $\mathbf{S}$, Lockee B et al. (2020): The difference between emergency remote teaching and online learning. Educause review, 27(27):1-2.

3. Malhotra A, Yarbrough T, Yang C (2020): Frontiers in faculty development: faculty learning communities to enhance technology-driven teaching for healthcare education. The FASEB Journal, 34: 1-1

4. Parrish A, Sadera W (2019): A review of faculty development models that build teacher educators' technology competencies. Journal of Technology and Teacher Education, 27(4):437-464.

5. Sattar K, Sethi A, Akram A et al. (2019). Flipped Classroom Teaching Modality: Key Concepts and Practice Endorsements. Education in Medicine Journal, 11(1):1-10

6. Johnson L, Adams Becker S, Estrada V et al. (2015). NMC Horizon Report: 2015 Higher Education Edition. Austin, TX: The New Media Consortium. Retrieved from: http://www.nmc.org/publication/nmc-horizonreport-2015-higher-education- edition/

7. Rotellar C, Cain J (2016): Research, perspectives, and recommendations on implementing the flipped classroom. American journal of pharmaceutical education, 80(2):1-10

8. Kamel A (2016): Role of faculty development programs in improving teaching and learning. Saudi Journal of Oral Sciences, 3(2): 61-68

9. Ahmed S, Shehata M, Hassanien M (2020): Emerging faculty needs for enhancing student engagement on a virtual platform. Retrieved from: https://mededpublish.org/articles/9-75

10. Steinert Y (2020): Faculty development: from rubies to oak. Medical teacher, 42(4): 429-435.

11. Reilly J, Vandenhouten $C$, Gallagher-Lepak $S$ et al. (2012): Faculty development for e-learning: A multicampus community of practice (COP) approach. Journal of Asynchronous Learning Networks, 16(2): 99-110.

12. Kirkpatrick D, Kirkpatrick J (2006): Evaluating training programs: The four levels. Berrett-Koehler Publishers.

https://www.bkconnection.com/static/Evaluating_Trai ning Programs EXCERPT.pdf

13. Schlegel E (2020): Designing online courses: 12 tips for health professions educators. MedEdPublish, 9.117

14. Sáiz-Manzanares M, Escolar-Llamazares M, Arnaiz González Á (2020): Effectiveness of blended learning in nursing education. International journal of environmental research and public health, 17(5): 1589:1-15

15. Samarasekera D, Lee S, Findyartini A et al. (2020). Faculty development in medical education: an environmental scan in countries within the Asia pacific region. Korean journal of medical education, 32(2):119-130 